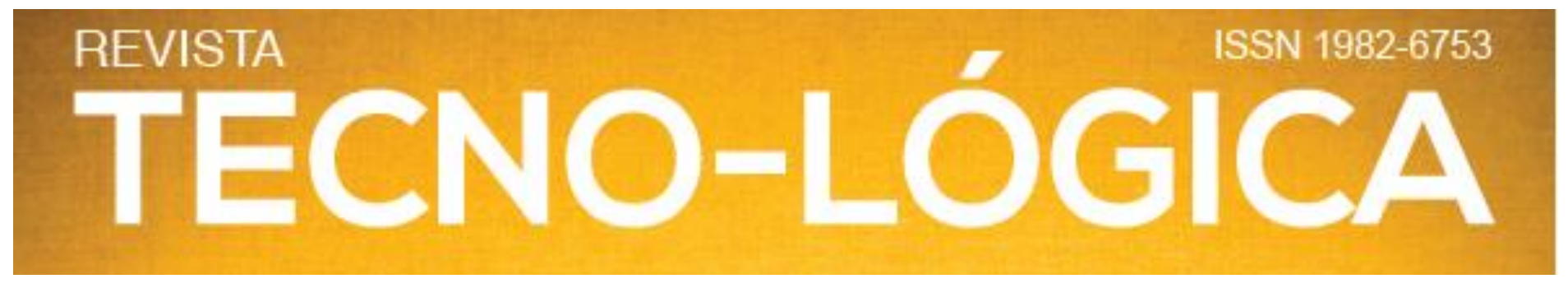

\title{
DIFERENTES TEMPERATURAS DE ÁGUA DE IRRIGAÇÃO NA CULTURA DO FEIJOEIRO
}

\author{
Cassiano Spaziani Pereiral ${ }^{*}$, Douglas de Oliveira ${ }^{2}$, Ivan Vilela Andrade Fiorini ${ }^{3}$, Adriano Alves da Silva ${ }^{4}$, Hélcio Duarte Pereira ${ }^{5}$ \\ 1,2,3,5ICAA- Instituto de Ciências Agronômicas e Ambientais, UFMT, campus Sinop MT, Brasil. \\ ${ }^{4}$ UNIFOR - Centro Universitário de Formiga MG, Brasil
}

*E-mail: ccaspaziani@yahoo.com.br

\section{RESUMO}

Dentre os períodos de semeadura do feijão, o considerado "inverno" ou "irrigado" é aquele semeado no período sem chuvas de maio a setembro, necessitando exclusivamente de irrigação. A forma mais comum de irrigação do feijão de "inverno" ocorre por meio de pivôs centrais de irrigação, nestes sistemas a água caminha longas distâncias advindas de corpos d'água chegando as plantas com as mais distintas características físicas, químicas e de temperatura. Diante disso, o objetivo do trabalho foi verificar a influência de diferentes temperaturas da água de irrigação, sobre o feijoeiro comum cultivar Dama. O experimento foi conduzido na casa de vegetação do Viveiro Florestal da Universidade Federal do Mato Grosso (UFMT), campus Sinop e utilizou-se como tratamento a irrigação de plantas de feijoeiro em vasos de 8 Litros, distribuídos em quatro blocos ao acaso no período entre os meses de junho e julho. Aplicaramse as seguintes temperaturas: $10^{\circ} \mathrm{C}, 15^{\circ} \mathrm{C}, 20^{\circ} \mathrm{C}, 25^{\circ} \mathrm{C}, 30^{\circ} \mathrm{C}, 35^{\circ} \mathrm{C}$ e $40^{\circ} \mathrm{C}$. A irrigação com as diferentes temperaturas foi realizada desde a semeadura, até o início do florescimento, estádio R1. Foi avaliado o crescimento vegetativo das plantas (altura; número de folhas; área foliar e massa seca da parte aérea), a massa seca radicular e os teores de clorofila Clorofilog ${ }^{\circledR}$. A variação de temperatura da água de irrigação de $10^{\circ} \mathrm{C}$ até $40^{\circ} \mathrm{C}$ não alteraram as variáveis altura de plantas, diâmetro de caule, número de folhas e massa seca de parte aérea. A água aplicada com temperatura de $30^{\circ} \mathrm{C}$ fez as plantas atingirem maior peso de raiz, já o tratamento de $35^{\circ} \mathrm{C}$ apresentou melhores resultados para índice de clorofiloG ${ }^{\circledR}$.

Palavras-chave: Phaseolus vulgaris. Temperaturas das águas. Irrigação. Crescimento vegetativo.

\section{Introdução}

O gênero Phaseolus corresponde cerca de 55 espécies de feijão, dentre estas espécies o feijão comum Phaseolus vulgaris L, é a mais conhecida e cultivada no Brasil. Segundo CONAB COMPANHIA NACIONAL DE ABASTECIMENTO [1], o Brasil é o maior produtor mundial de feijão comum, produzindo mais que países como a Índia e China e se somarmos os três ciclos da cultura, a produção de feijão na safra 2018/2019 atingiu 3.098 milhões de toneladas. Os estados do Paraná, Minas Gerais e Bahia são os maiores produtores, correspondendo a $50 \%$ da produção nacional, porém a produção em Mato Grosso vem crescendo. As lavouras de feijão do estado do Mato Grosso aumentaram em 9,7\% a produção levando em conta as três safras, com a produtividade de aproximadamente $1.402 \mathrm{~kg} \mathrm{ha}^{-1}$, em Mato Grosso entre os anos 2018/2019 e a área destinada ao cultivo de feijão-comum cores na segunda safra 2019/2020 foi de aproximadamente 27,6 mil hectares.

O consumo de feijão comum ocorre no Brasil, principalmente pelo fato de neste grão se encontrar altas quantidades de carboidratos proteína, e ser rico em ferro. Estudos sobre nutrição da Embrapa apontaram que a cada $100 \mathrm{~g}$ de feijão cru, se contêm em média $22 \mathrm{~g}$ de proteína, $61 \mathrm{~g}$ de carboidrato, 4.3 $\mathrm{g}$ de fibras, além de outros nutrientes como ferro e fósforo.

No começo dos anos 2000 aconteceu uma expansão da irrigação por pivôs centrais no Brasil, ampliando a safra de 'inverno' ou outono inverno, isso devido à facilidade operacional, pelo controle de lâmina de água, e eficiência da no uso da água segundo a ANA-AGÊNCIA NACIONAL DE ÁGUAS [2] e com dados divulgados pela mesma em 2014 no Brasil, existiam cerca de 4.530 outorgas válidas para irrigação, com o feijão irrigado

A matéria publicada nesse periódico é licenciada sob forma de uma Licença Creative Commons - Atribuição 4.0 Internacional http://creativecommons.org/licenses/by/4.0/ 


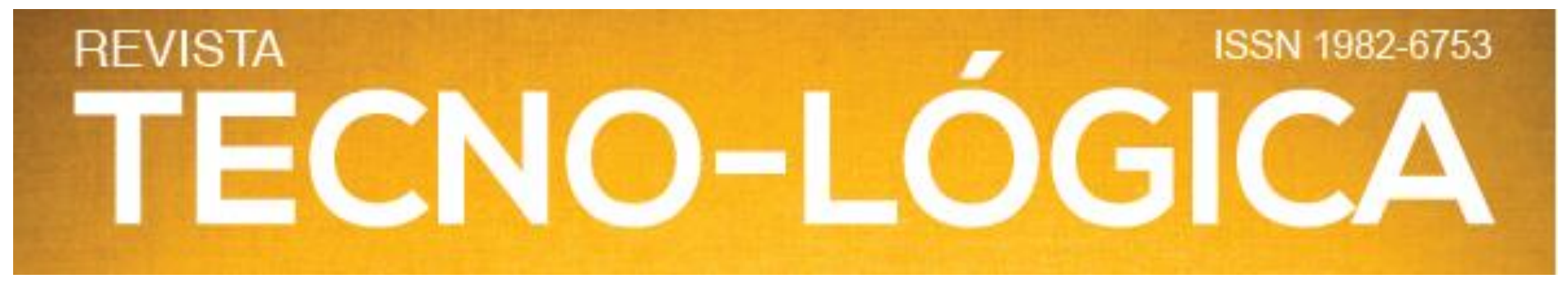

representando $20.5 \%$ das culturas irrigadas, assim destacando a importância da irrigação para essa cultura em plantios de inverno.

O feijão é exigente em clima tropical de temperatura média de $25^{\circ} \mathrm{C}\left(18^{\circ} \mathrm{C}\right.$ a $\left.30^{\circ} \mathrm{C}\right)$ precipitação de $100 \mathrm{~mm}$ de forma distribuída. O feijão é sensível ao estresse hídrico, com reduzida capacidade de recuperação, sistema radicular pouco desenvolvido. O excesso de água no solo devido á irrigação mal planejada resulta em prejuízos para a cultura, uma vez que esta planta é sensível ao excesso hídrico (com consequente má aeração do solo), principalmente na fase de florescimento ao enchimento de grãos, prejudica diretamente a germinação e limita o desenvolvimento das raízes, favorece a incidência de doenças radiculares e reduz a sobrevivência de plântulas [3].

Durante a irrigação muitos fatores podem influenciar na eficiência da irrigação e qualidade da água, tais como o excesso de matéria orgânica, a presença em excesso de calcário (água dura) causando o entupimento dos bicos de irrigação (problemas no sistema de irrigação), e excesso de sais de sódio, além de trazer prejuízos às propriedades físicas e químicas do solo, provoca a redução generalizada do crescimento das plantas cultivadas provocando sérios prejuízos à atividade agrícola [4]. Contudo, o grau ou a concentração de sais que determinam essa redução varia com a espécie, podendo esse fato estar relacionado com a tolerância de cada espécie à salinidade [5].

Outro fator que pode se alterar é o $\mathrm{pH}$ da água que deve estar em torno de 6,5 e 8,4 (ora desta faixa seria um indicador de anormalidade na qualidade da água ou presença de íons tóxicos podendo agir negativamente na população microbiana do solo e danos ao sistema radicular) [6].

Inúmeros outros fatores relacionados a água de irrigação podem estar correlacionados com a produtividade dos cultivos, isso sem contar a presença de patógenos, que via água de irrigação podem dizimar um cultivo. Diante disso, o objetivo deste trabalho foi determinar a influência e importância da temperatura da água no momento da irrigação sobre o crescimento vegetativo, formação de raízes e os teores de clorofila (Clorofilog $G^{\circledR}$ ), uma vez que inexistem trabalhos de pesquisa que avaliem este fator recente demanda do tema devido ao aumento da temperatura ocasionada pelo aquecimento global.

\section{Metodologia}

O experimento foi conduzido na casa de vegetação do Viveiro Florestal da UFMT campus Sinop. Antes do início do experimento foi coletado solo próximo à área, peneirado em peneira fina e antes de ser colocado nos vasos, retirou-se uma amostra para a análise química do solo. Com a amostra obteve-se os seguintes valores: $\mathrm{pH}\left(\mathrm{H}_{2} \mathrm{O}\right) 4,4 ; \mathrm{P}$ (total) 1,30 $\mathrm{mg} \mathrm{dm}^{-3} ; \mathrm{K} \mathrm{6,00}$

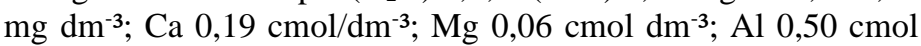

$\mathrm{dm}^{-3}$; H 5,57 $\mathrm{cmol} \mathrm{dm}^{-3}$; H+Al 6,07 $\mathrm{cmol} \mathrm{dm}^{-3} ; \mathrm{V}: 4,20 \%$. Os

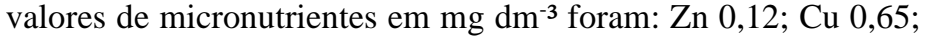
Fe 143,50; Mn 3,98; B 0,10. Após os resultados da análise fez a correção do solo com calcário com aplicação de $1 \mathrm{~kg}$ de calcário magnesiano para $224 \mathrm{~kg}$ de solo, para reduzir a acidez do solo e corrigir o pH do solo. Após a aplicação e mistura do calcário no solo esperou-se por um período de 20 dias, irrigando-se o solo a cada 2 dias para reação do calcário e posterior implantação do experimento.

O experimento foi semeado no dia 01 de junho até a colheita das plantas no florescimento pleno no dia 27 de julho de 2019. Na semeadura foi utilizado o feijão comum Phaseolusvulgaris L., variedade Dama. O experimento foi instalado na casa de vegetação em um telado coberto com plástico transparente de $150 \mu \mathrm{m}$ e o entorno cercado por sombrite $50 \%$. Para condução das plantas utilizou-se vasos de 8 Litros, que ficaram sobre uma mesa de madeira a 1,2 $\mathrm{m}$ do solo, espaçados 30 $\mathrm{cm}$ entre si distribuídos ao acaso, com um total de 4 repetições por tratamento, sendo realizados 7 tipos de diferentes temperaturas.

Os vasos possuíam volume de 8L. Como forma de obtenção da capacidade de campo (CC), foi adotado o método de conteúdo de água no solo após sofrer saturação através da ação da gravidade, até o cessamento da drenagem. Para isso, coletou-se 8 $\mathrm{kg}$ do solo a ser utilizado no experimento e realizou-se a secagem do mesmo ao sol. Posteriormente o solo foi saturado de água e deixado sem interferências até cessar a drenagem, após este tempo, a massa do solo foi obtida. A reposição da água foi feita de acordo com a necessidade de cada por tratamento, com turno de rega a cada dois dias.

A quantidade inicial foi de aproximadamente $1 \mathrm{~L}$, com variações de $200 \mathrm{~mL}$ para mais ou para menos conforme o desenvolvimento da planta. $\mathrm{O}$ turno de rega ocorria em intervalos de 1 dia, aumentando o período do turno sempre que necessário, quando por exemplo se percebia que o solo estava mais seco que o normal, evitando deixar o solo dos vasos úmido para não ocorrer desperdícios ou exageros na irrigação perdendo-se o controle do total de água aplicado nos tratamentos.

O delineamento experimental foi em blocos ao acaso com quatro repetições, sendo estas diferentes temperaturas de água de irrigação: $10^{\circ} \mathrm{C} ; 15^{\circ} \mathrm{C} ; 20^{\circ} \mathrm{C} ; 25^{\circ} \mathrm{C} ; 30^{\circ} \mathrm{C} ; 35^{\circ} \mathrm{C}$ e $40^{\circ} \mathrm{C}$. Para irrigação utilizava-se sempre a mesma água encanada e filtrada disponível num bebedouro no Viveiro da UFMT. A água tinha com pH entre 5,5 e 6,0 obtido através do auxílio de um pHmetro e temperatura de aproximadamente $9^{\circ} \mathrm{C}$ que era corrigida inicialmente para $10^{\circ} \mathrm{C}$ e depois para as temperaturas mais elevadas com o auxílio de uma serpentina elétrica metálica tornado possível a obtenção das temperaturas dos tratamentos desejados realizando-se o aquecimento da água e rápida armazenagem da 


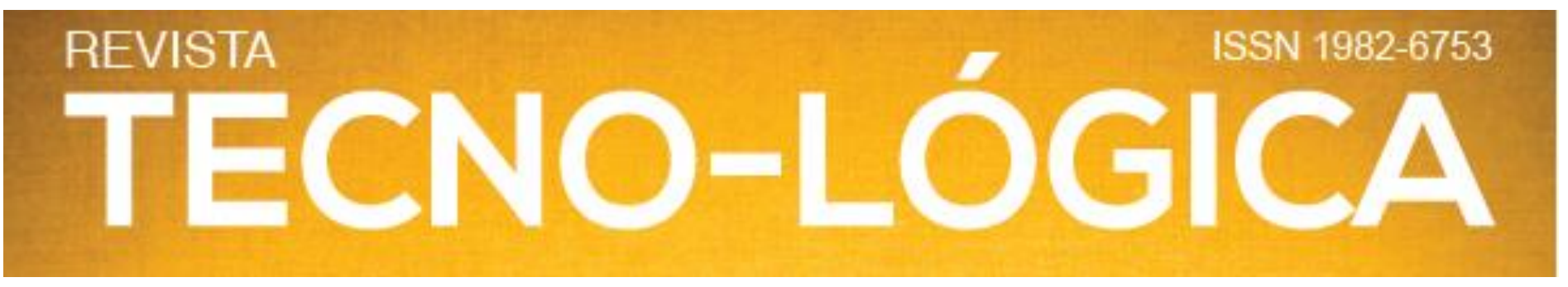

mesma em uma garrafa térmica e rápida aplicação da água nas plantas, para evitar variações nas temperaturas utilizadas.

$\mathrm{Na}$ semeadura utilizou-se 3 sementes por vasos, realizando-se o raleio em VE para duas plantas por vaso e posteriormente no dia 18 realizado o desbaste permanecendo uma planta por vaso. A adubação ocorreu no dia da semeadura e foi através da aplicação de $40 \mathrm{~g}$ do formulado N P K: 4-14-8 incorporado no solo por vaso, calculados de acordo com a necessidade da cultura (100 kg de N, $120 \mathrm{~kg}$ de P e $90 \mathrm{~kg} \mathrm{ha}^{-1}$ de $\mathrm{K})$.

Os tratamentos de irrigação iniciaram logo após o semeio, no dia da semeadura 10 de junho foi realizada a inoculação das sementes com Rhizobium tropici na concentração de $1 \times 10^{9}$ UFC $\mathrm{mL}^{-1}$, utilizando $1 \mathrm{~mL}$ por vaso, para evitar danos por insetos, principalmente Diabrotica spp fez-se a aplicação de inseticida no dia 14 de junho com inseticida Mustang® 350 EC do grupo das Zeta-Cipermetrinas na dose de $1,5 \mathrm{~mL}$ para $2 \mathrm{~L}$ de água, sendo suficiente para proteger o experimento todo. Todas as avaliações foram realizadas durante o estádio $\mathrm{R} 1$ do feijão comum quando as plantas estavam no início do florescimento. Avaliou-se o teor de clorofila (cor das folhas) e o crescimento vegetativo.

As análises do teor de clorofila (cor verde das folhas) das plantas do feijão comum foram efetuadas, com o auxílio do aparelho ClorofiLOG®, modelo CFL 1030. Foram tomados 4 pontos de amostra no primeiro trifólio totalmente expandido de cada planta das parcelas. Os resultados foram expressos em Índice de Clorofila Falker (ICF) que é adimensional.

A altura das plantas foi obtida com auxílio de uma régua flexível graduada, medindo-se do solo até o meristema apical das plantas. Foram tomadas as alturas das quatro plantas da parcela e depois das medições obteve-se a altura média por parcela, com os resultados expressos em $\mathrm{cm}$. O diâmetro de caule foi obtido $5 \mathrm{~cm}$ de altura do solo com auxílio de um paquímetro digital, tomandose os valores das quatro plantas da parcela e os resultados foram expressos em mm planta $^{-1}$.

Após as medições realizadas na casa de vegetação, as plantas foram cortadas rente ao solo, acondicionadas em sacolas de papel e levadas para o laboratório do Viveiro Florestal da UFMT. No laboratório as folhas das plantas foram destacadas e contadas, obtendo-se o número de folhas plantas ${ }^{-1}$, logo após obteve-se a área foliar em $\mathrm{cm}^{2}$, com o auxílio de um integrador de área foliar LICOR modelo LI-3010. Por fim as amostras foliares foram recondicionadas em sacos de papel e colocadas em estufa de circulação de ar forçado a $60^{\circ} \mathrm{C}$, até atingirem o peso constante, para obtenção da massa seca da parte aérea [7].

O solo com as raízes das plantas foi retirado dos vasos e através de um processo de lavagem em água corrente, separou-se o solo das raízes. As raízes foram armazenadas separadamente em sacos de papel e colocadas em estufa de circulação de ar forçado por 96 horas a $65^{\circ} \mathrm{C}$, obtendo-se a massa seca das raízes. Após todas as análises, os dados obtidos foram submetidos à análise de variância ao nível de $5 \%$ de probabilidade com o auxílio do software SISVAR ${ }^{\circledR}$ [8]. As variáveis foram quantitativas e os modelos foram escolhidos e baseados na significância dos coeficientes de regressão utilizando o teste " $\mathrm{t}$ " adotando-se o nível de $5 \%$ de probabilidade de determinação, o valor do $\mathrm{r}^{2}$ (SQRegressão/SQtratamentos).

\section{Resultados e discussões}

Com a obtenção das variáveis e análise de variância, verificou-se que a área foliar, altura de plantas e diâmetro de caule não foram influenciadas pela temperatura da água no momento da irrigação (Tabela 1). Para os teores de clorofila verificou-se diferença significativa, com a alteração na temperatura da água de irrigação. Com relação às médias das variáveis analisadas no período vegetativo em estádio fisiológico de início de florescimento em $\mathrm{R} 1$ : número de folhas, massa seca de raiz (MSRA), massa seca parte área (MSPA), verificou-se através da análise de variância que apenas variável massa seca de raiz, foi alterada pela alteração nas temperaturas de água de irrigação (Tabela 2).

Tabela 1 - Valores de quadrado médio e significância estatística das variáveis: altura de plantas, ClorofiloGß, diâmetro de caule e área foliar.

\begin{tabular}{llllcc}
\hline FV & GL & \multicolumn{3}{c}{ Quadrados médios } \\
\cline { 3 - 6 } & & Altura de plantas & ClorofiloG ${ }^{\circledR}$ & Diâmetro de Caule & Área foliar \\
\hline Híbridos & 6 & 220,38 & $23,5220^{* *}$ & 0,1860 & 2,4672 \\
Blocos & 3 & 1400,74 & 7,1428 & 0,8177 & 4,9375 \\
Erro & 18 & 277,12 & 5,5175 & 0,3021 & 3,5625 \\
\hline Total & 27 & & & 11,38 & 26,10 \\
\hline CV & & 22,75 & 6,07 &
\end{tabular}

Os quadrados médios seguidos de * ou **, apresentaram diferenças significativas a 5 e $1 \%$ de probabilidade. 


\section{REVISTA}

Tabela 2 - Valores de quadrado médio e significância estatística das variáveis: número de folhas, massa seca de raiz (MSRA), massa seca parte área (MSPA).

\begin{tabular}{llccc}
\hline FV & GL & \multicolumn{2}{c}{ Quadrados médios } & MSPA \\
\cline { 3 - 5 } & & Número de folhas & MSRA & 0,4412 \\
Híbridos & 6 & 2,4672 & $16,9590^{* *}$ & 3,6631 \\
Blocos & 3 & 4,9374 & 7,0331 & 0,9582 \\
Erro & 18 & 3,5625 & 5,3664 & 14,90 \\
\hline Total & 27 & & & 23,80 \\
\hline CV & & 26,10 & &
\end{tabular}

Os quadrados médios seguidos de * ou **, apresentaram diferenças significativas a 5 e $1 \%$ de probabilidade

Com a obtenção dos valores do índice ClorofiloG® se pode observar que o tratamento com temperatura de $30^{\circ} \mathrm{C}$ atingiu a maior concentração de clorofila e consequentemente um maior teor de $\mathrm{N}$, com o valor de 42.4 unidade, os demais tratamentos não demonstraram resultados significativos (Figura 1).

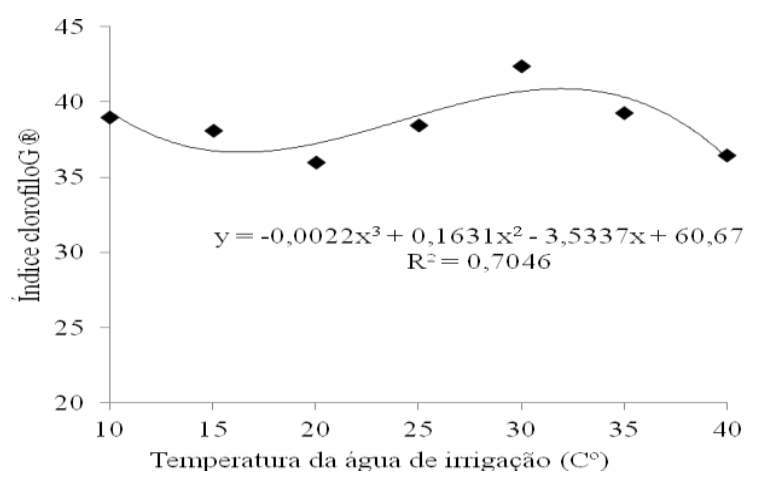

Figura 1: Comparação de resultados entre temperatura de água de irrigação e índice ClorofiloG® no quadrado médio. UFMT-SinopMT, 2019.

A clorofila é o pigmento mais abundante na natureza cujo principal papel é a absorção de luz solar e sua conversão para energia química durante a fotossíntese, processo este de grande importância para a vida terrestre. Sabe-se por relatos na literatura que plantas com metabolismo C3 (plantas que formam o 3fosfoglicerato como primeiro intermediário estável na fotossíntese) como do feijão, possuem maiores respostas fotossintéticas em temperaturas entre 20 a $30^{\circ} \mathrm{C}$, com isso temperaturas superiores a $30^{\circ} \mathrm{C}$ podem gerar menor assimilação de $\mathrm{CO}_{2}$ e a ação de efeitos deletérios como a degradação da molécula da clorofila [9].
As projeções de cenários climáticos para o futuro são que ocorrerá alteração no regime climático de todo o globo terrestre isto em decorrência das mudanças climáticas, havendo um aumento de 3 a $4^{\circ} \mathrm{C}$ na temperatura nos próximos 100 anos [10].

Temperaturas mais elevadas no solo podem afetar diferentes processos metabólicos, incluindo fotossíntese, respiração, relações hídricas, fluidez e estabilidade dos sistemas de membranas, além de modular os níveis de hormônios e de metabólicos primário e secundário [11].

Em relação a massa seca de raiz, observou-se o maior valor obtido na temperatura de $35^{\circ} \mathrm{C}$, com um peso de $12 \mathrm{~g}$ de MSRA, isso pelo fato de ser uma temperatura mais próxima da ambiente, não afetando diretamente as atividades biológicas do solo (Figura 2).

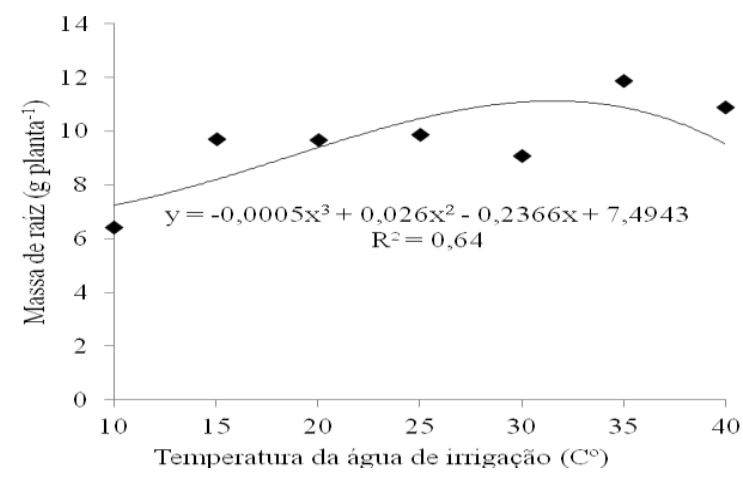

Figura 2: Comparação de resultados entre temperatura de água de irrigação e peso de massa de raiz no quadrado médio. UFMT Sinop-MT, 2019.

As temperaturas do solo inferior a $10^{\circ} \mathrm{C}$ e superior a $40^{\circ} \mathrm{C}$ prejudicam sensivelmente a germinação, sendo a faixa ideal a entre 25 e $30^{\circ} \mathrm{C}$ [12]. Além do processo de germinação as atividades biológicas do solo são afetadas diretamente ou

A matéria publicada nesse periódico é licenciada sob forma de uma Licença Creative Commons - Atribuição 4.0 Internacional http://creativecommons.org/licenses/by/4.0/ 


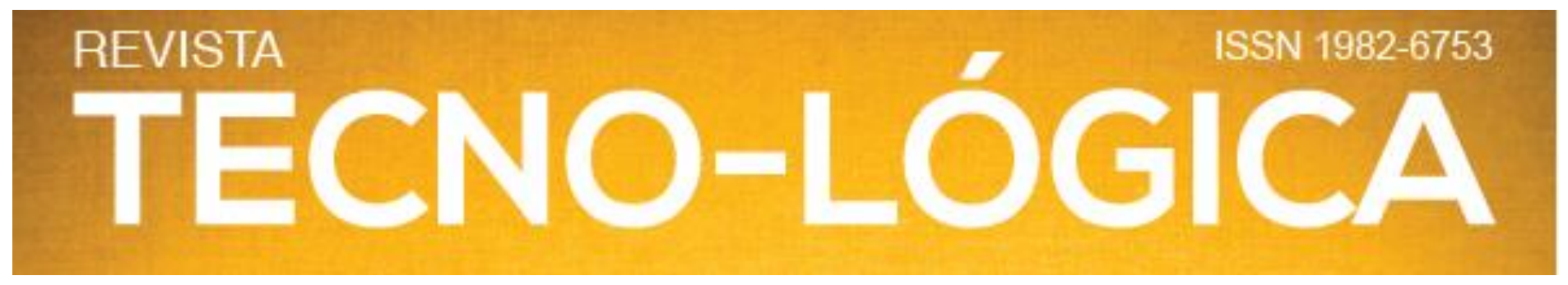

indiretamente pela temperatura ou pelo conteúdo de água do solo [13].

Não ocorreram resultados significativos ao nível de 5\% de probabilidade e utilizando o teste " $\mathrm{t}$ " para as temperaturas de água de irrigação para altura de plantas, número de folhas, índice de área foliar e massa seca de parte área. Os valores obtidos nos diferentes tratamentos não apresentaram diferença estatística (Figuras 3 a 7).

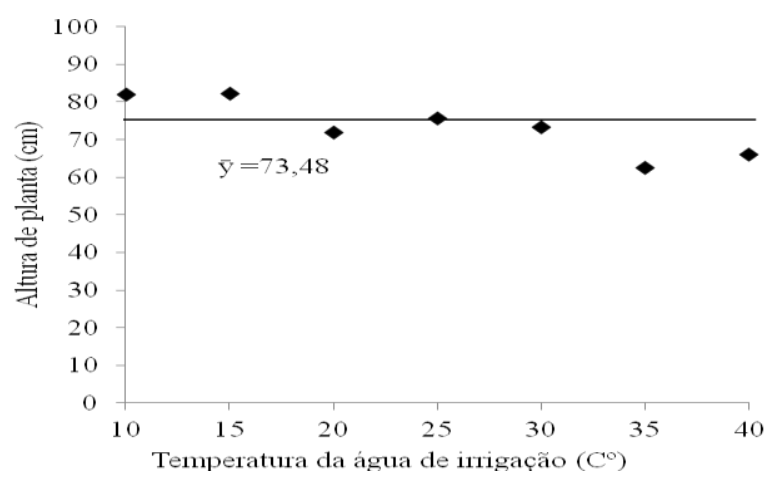

Figura 3: Comparação de resultados entre temperatura de água de irrigação e altura de planta $(\mathrm{cm})$ no quadrado médio. UFMTSinop-MT, 2019.

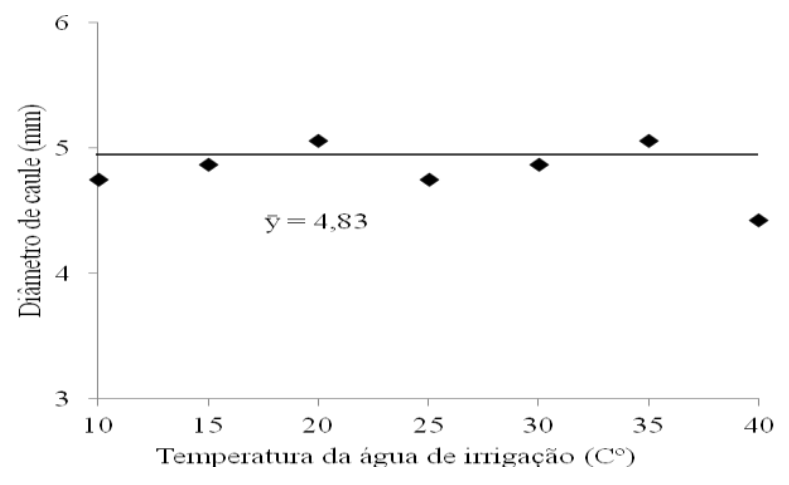

Figura 4: Comparação de resultados entre temperatura de água de irrigação e diâmetro de caule $(\mathrm{mm})$ no quadrado médio. UFMTSinop-MT, 2019.

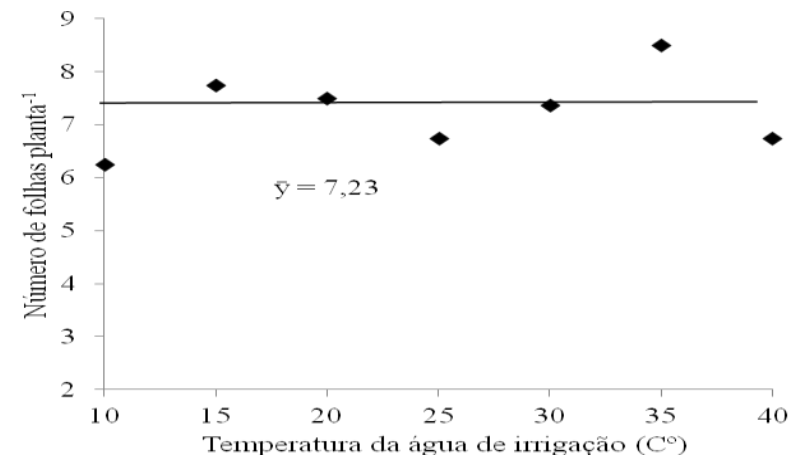

Figura 5: Comparação de resultados entre temperatura de água de irrigação e número de folhas no quadrado médio. UFMT-SinopMT, 2019.

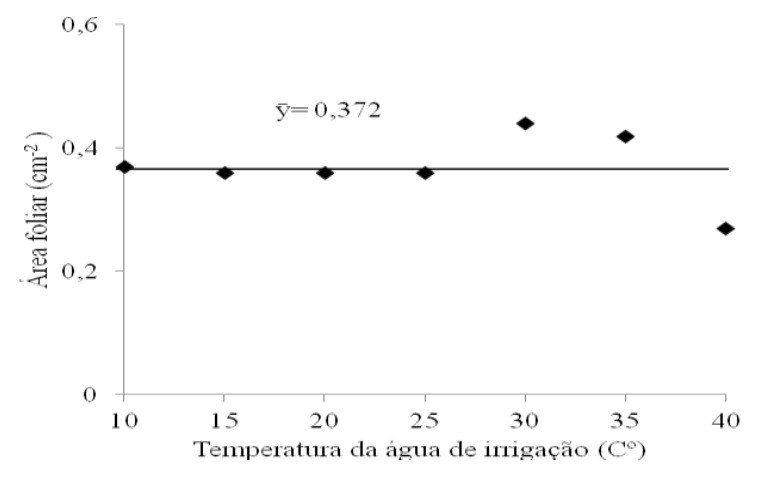

Figura 6: Comparação de resultados entre temperatura de água de irrigação e área foliar $\left(\mathrm{cm}^{-2}\right)$ no quadrado médio. UFMT-. UFMTSinop-MT, 2019.

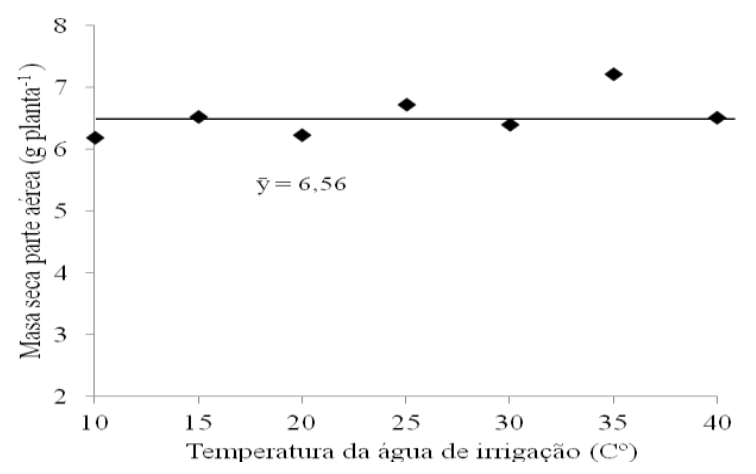

Figura 7: Comparação de resultados entre temperatura de água de irrigação e massa seca parte área ( $\left.\mathrm{g}_{\text {planta }}{ }^{-1}\right)$ no quadrado médio. UFMT-Sinop-MT, 2019. 


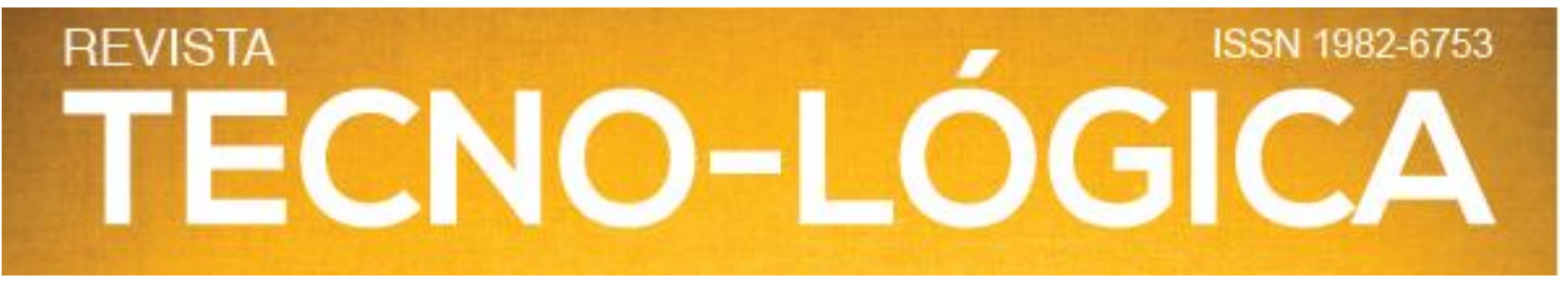

Os tratamentos de $30^{\circ} \mathrm{C}$ e $35^{\circ} \mathrm{C}$ apresentaram melhores resultados para valores de ClorofiloG ${ }^{\circledR}$ e massa seca de raiz respectivamente, nessa faixa de temperatura da água a atividade biológica se manteve ativa assim favorecendo o desenvolvimento da planta. Da mesma forma, houve maior atividade biológica nas raízes e a ação não afetou a inoculação e o oxigênio disponível à planta do feijão. Obteve-se um maior desenvolvimento de raiz, seguida de uma melhor fixação de nitrogênio apresentando números considerados ideais de índice de clorofila para a cultura.

\section{Conclusões}

A variação de temperatura da água de irrigação de $10^{\circ} \mathrm{C}$ até $40^{\circ} \mathrm{C}$ não alteraram as variáveis altura de plantas, diâmetro de caule, número de folhas e massa seca de parte aérea.

A água aplicada com temperatura de $30^{\circ} \mathrm{C}$ fez as plantas atingirem maior peso de raiz, já o tratamento de $35^{\circ} \mathrm{C}$ apresentou melhores resultados para índice de clorofiloG ${ }^{\circledR}$.

\section{DIFERENTS TEMPERATURE OF WATTERS IRRIGACION IN BEAN CROP}

ABSTRACT: Among the bean sowing periods, the one considered "winter" or "irrigated" is the one sown in the period without "rains" from May to September, needing only irrigation. The most common form of irrigation of "winter" beans occurs through central irrigation pivots, in these systems the water walks long distances from bodies of water, reaching plants with the most distinct physical, chemical and even temperature characteristics. Therefore, the objective of the work was to verify the influence of different temperatures of the irrigation water, on the common bean cultivar Dama. The experiment was carried out in the greenhouse at UFMT and the irrigation of common bean plants in $8 \mathrm{~L}$ pots was used as treatment, distributed in four random blocks between June and July. The following temperatures were applied: $10^{\circ} \mathrm{C}, 15^{\circ}$ $\mathrm{C}, 20^{\circ} \mathrm{C}, 25^{\circ} \mathrm{C}, 30^{\circ} \mathrm{C}, 35^{\circ} \mathrm{C}$ and $40^{\circ} \mathrm{C}$. Irrigation with different temperatures was carried out from sowing to the beginning of flowering, stage R1. The vegetative growth of the plants (height; number of leaves; leaf area and dry mass of the aerial part, the root dry mass) and the levels of chlorophyllß were evaluated. There were no statistical differences in the variables, height, diameter, leaf area, number of leaves and dry mass of aerial part. The water applied at a temperature of $30^{\circ} \mathrm{C}$ made the plants reach a higher root weight, whereas the treatment of $35^{\circ} \mathrm{C}$ showed better results for the chlorophyll@ index.
Keywords: Phaseolus vulgaris. Water temperatures. Irrigation. Vegetative growth.

\section{Referências}

[1] CONAB - COMPANHIA NACIONAL DE ABASTECIMENTO. Acompanhamento da safra brasileira: grãos: safra 2018/2019: $8^{\circ}$ Levantamento da safra 2018/19. Brasília, DF, 2019. Disponível em: <http://www.conab.gov.br/OlalaCMS/uploads/arquivos/17_04_17_17_20_55_bol etim_graos_ago_2019.pdf_boletim_portugues_-_set de_2019.pdf >. Acesso em: 12 de outubro de 2019 .

[2] AGÊNCIA NACIONAL DE ÁGUAS (Brasil). Conjuntura dos recursos hídricos no Brasil: Informe 2013. Brasília: ANA, 2014, 432.

[3] LEVANTAMENTO SISTEMÁTICO DA PRODUÇÃO AGRÍCOLA 2020. Disponível em: < https://sidra.ibge.gov.br/tabela/1618> Acesso em: fev.2020.

[4] CAVALCANTE, L. F. Sais e seus problemas nos solos irrigados. Areia: UFPB, 2000. $71 \mathrm{p}$.

[5] FERREIRA, R. G.; et al. Distribuição da matéria seca e composição química das raízes, caule e folhas de goiabeira submetida a estresse salino. Pesquisa Agropecuária Brasileira, v. 36, n. 1, p. 79-88, 2001.

[6] JUNIER, P. et al. Composition of diazotrophic bacterial assemblages in beanplanted soil compared to unplanted soil. European Journal of Soil Biology, v. 45, n. 2, p. 153-162, 2009.

[7] PEREIRA, C. S.; FARIAS, F. L.; GODOI, C. A. Aplicação de extrato etanólico de própolis (EEP) na nutrição e desenvolvimento de mudas de cafeeiro. Coffee Science, v. 9, $\mathrm{n}^{\circ} 1$, p. 14-23, 2014.

[8] FERREIRA, D.F. Sisvar: A computer statistical analysis system. Ciência e Agrotecnologia, v. 35, n. 1, p. 1039-1042, 2011.

[9] BORRMANN, D. Efeito do déficit hídrico em características químicas e bioquímicas da soja e na degradação da clorofila, com ênfase na formação de metabólitos incolores. 2009. 125 f. Tese (Doutorado em Ciências dos Alimentos) - Faculdade de Ciências Farmacêuticas, Universidade de São Paulo, São Paulo.

[10] NOBRE, C. A. Mudanças climáticas globais: possíveis impactos nos ecossistemas do país. Parcerias estratégicas, v. 6, n. 12, p. 239-258, 2010.

[11] WAHID, A.; GELANI, S.; ASHRAF, M.; FOOLAD, M.R. Heat tolerance in plants: An overview. Environmental and Experimental Botany, v.61, p.199-223. 2007.

[12] FANCELLI, A.L.; DOURADO NETO, D. Ecofisiologia e fenologia. In: FANCELLI, A.L.; DOURADO NETO, D. (Ed.) Produção de milho. Guaíba: Agropecuária, 2000. p. 21-54.

[13] HORST, W.J; KAMH, M; JIBRIN,J.M; CHUDE, V.O. Agronomic measurements for increasing P availability to crops. Plant and Soil, v.237, p. 211$223,2001$. 